\title{
Survival Analysis \\ Survival from non-Hodgkin lymphoma in England and Wales up to 2001
}

\author{
B Rachet', E Mitry², A Shah', N Cooper ${ }^{3}$ and MP Coleman*,I \\ 'Cancer Research UK Cancer Survival Group, Non-Communicable Disease Epidemiology Unit, Department of Epidemiology and Population Health, \\ London School of Hygiene and Tropical Medicine, Keppel Street, London WCIE 7HT, UK; 'Département d'Hépatogastroentérologie et Oncologie \\ Digestive, Centre Hospitalo-Universitaire Ambroise-Paré, 9 avenue Charles de Gaulle, Boulogne F-92 I 00, France; ${ }^{3}$ Social and Health Analysis and \\ Reporting Division, Office for National Statistics (Room FG/I I 4), I Myddelton Street, London ECIR IUW, UK
}

British Journal of Cancer (2008) 99, SI04-SI06. doi:I0.1038/sj.bjc.6604605 www.bjcancer.com

Published online 23 September 2008

(c) 2008 Cancer Research UK

Non-Hodgkin lymphoma comprises a disparate set of malignancies of lymphoid tissue, other than Hodgkin's disease, with a wide variety of biological, clinical and prognostic features. The clinical classification of lymphomas has changed considerably in response to advances in medical knowledge, but it has been difficult to assimilate these changes into the International Classification of Diseases (ICD) for Oncology, used by population-based cancer registries for coding cases for international comparison of cancer incidence (Percy et al, 1984). The tenth revision of the ICD provided more rubrics for non-Hodgkin lymphoma (C82-C85, C91.4, C96) than the two available in ICD-9 $(200,202)$, but cancer registry data were only coded to ICD-10 from 1995 or later.

As a result, it is not yet possible to provide long-term comparisons of incidence and survival trends for specific types of non-Hodgkin lymphoma with population-based data. This is also true of mortality data, which were only coded to ICD-10 from 2000 or later, and which are derived from the limited diagnostic information on death certificates, as opposed to the medical records used to register newly diagnosed cases. Mortality data are generally reported for all the non-Hodgkin lymphomas combined. We present survival trends for the same broad category of all the non-Hodgkin lymphomas combined.

Non-Hodgkin lymphoma is the most common lympho-haemopoietic malignancy in adults. It ranks as the eighth most common malignancy with almost 8000 new cases diagnosed each year. The male-female ratio is approximately 1.5. Non-Hodgkin lymphoma has tripled in frequency in both sexes since the early 1970s (Quinn et al, 2001), an increase echoed in many countries (Coleman et al, 1993). More than $60 \%$ of cases arise in persons aged 60 years or more, and the increase in incidence has been up to five-fold in older men and women, with little change in young adults. Incidence is slightly higher in affluent than deprived men, but there is no difference for women.

The causes of NHL are not well established, although solvents, pesticides and other chemicals have been implicated (Blair and Kazerouni, 1997; Lynge et al, 1997; Stellman, 1998). Certain viruses, such as Epstein-Barr virus, HIV and HTLV are known to be potentially lymphoma-inducing (IARC, 1996, 1998), whereas oncogenic viruses have recently been suspected (Metayer et al, 1998).

*Correspondence: Professor MP Coleman;

E-mail: michel.coleman@Ishtm.ac.uk
We analysed the data for 78894 patients registered with nonHodgkin lymphoma as a first primary malignancy in England and Wales during the period $1986-1999$, some $86 \%$ of those eligible. Nine per cent of cases were excluded from survival analysis because their recorded survival was zero (date of diagnosis same as date of death): most of these will have been registered from a death certificate only (DCO); hence, their date of diagnosis and their duration of survival were both unknown. These cases could not be reliably distinguished from cases with true zero survival in the national data. The proportion of cases excluded from analysis as DCO was similar in all deprivation groups, and this is unlikely to have had a material impact on estimates of trend or socioeconomic gradient in survival. A further $3 \%$ of patients were excluded because the lymphoma was not their first primary malignancy, along with $1.8 \%$ whose vital status was unknown at 5 November 2002, when the data were extracted for analysis.

\section{SURVIVAL TRENDS}

One-year survival rose from 66 to $70 \%$ in both sexes: after adjustment for differences among deprivation groups, that represents an increase of approximately $2 \%$ every 5 years (Table 1 , Figure 1). Five-year survival rose more quickly than 1-year survival, from $46 \%$ for patients diagnosed during 1986-1990 to approximately $52 \%$ for those diagnosed during 1996-1999, a deprivation-adjusted increase of approximately $4 \%$ every 5 years. Both rates of increase are statistically significant. For patients diagnosed during 1996-1999, the 5-year relative survival reached $51 \%$ for men and $53 \%$ for women.

Hybrid analysis of the survival probabilities observed during 2000-2001 (Brenner and Rachet, 2004) suggests that the recent improvement in survival observed during the late 1990s is likely to continue (Figure 1, dashed line). Survival rates predicted for those diagnosed during 2000-2001 are approximately $70-71 \%$, 53-54\% and $44-45 \%$ at 1,5 and 10 years after diagnosis, respectively (Table 1 ).

\section{DEPRIVATION}

Survival at 1, 5 and 10 years after diagnosis is substantially and systematically higher among more affluent groups. Among more than 26000 patients diagnosed during 1996-1999, the 
Table I Trends in relative survival (\%) by sex, time since diagnosis and calendar period of diagnosis: England and Wales, adults (I5-99 years) diagnosed during 1986-1999 and followed up to 2001

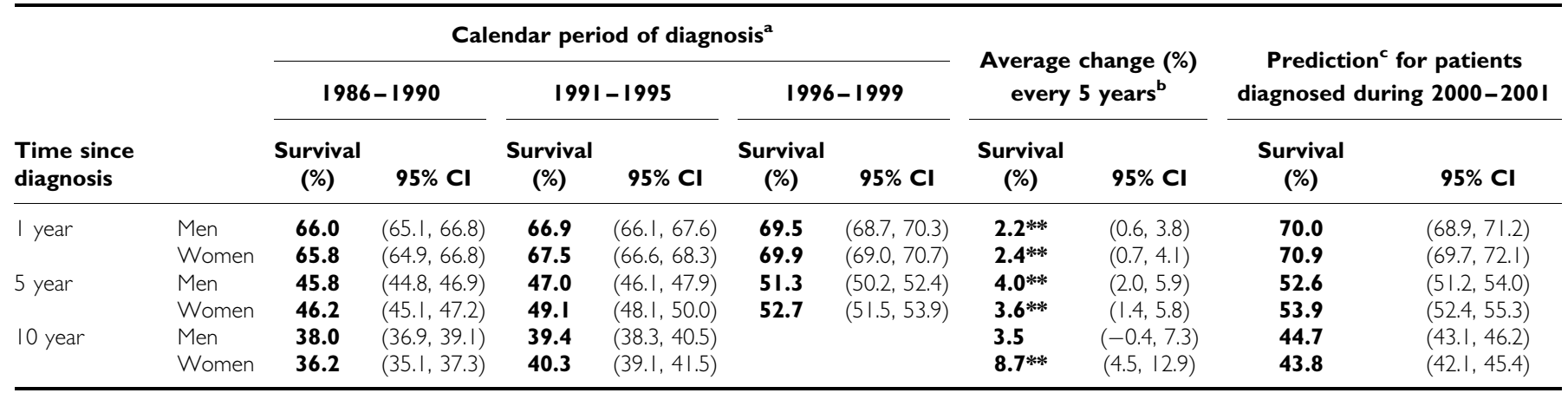

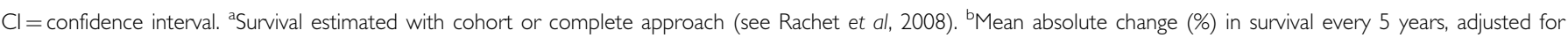
deprivation (see Rachet et al, 2008). 'Survival estimated with hybrid approach (see Rachet et al, 2008). ${ }^{*} * P<0.01$.

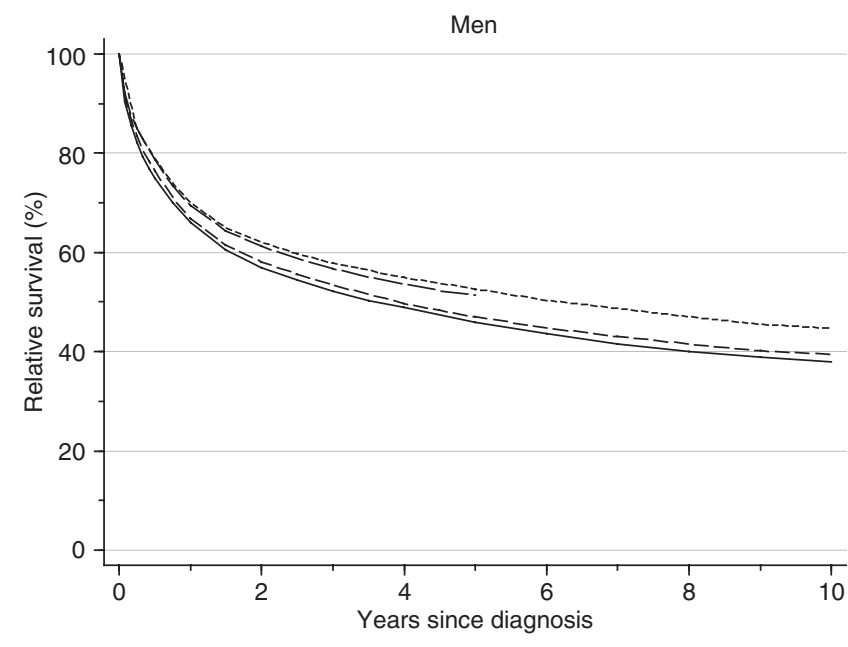

Women

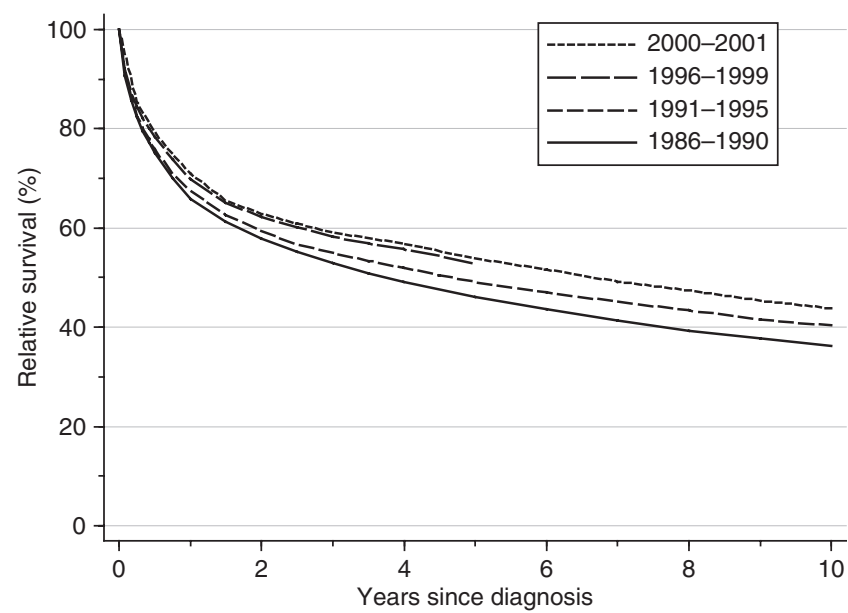

Figure I Relative survival (\%) up to 10 years after diagnosis by sex and calendar period of diagnosis: England and Wales, adults (15-99 years) diagnosed during 1986-1999 and followed up to 200 I. Survival estimated with cohort or complete approach (1986-1990, 1991-1995, 1996-1999) or hybrid approach (2000-200I) (see Rachet et al, 2008).

differences in 1- and 5-year survival between the most deprived and the most affluent groups were estimated at 5-7\% (Table 2, Figure 2).
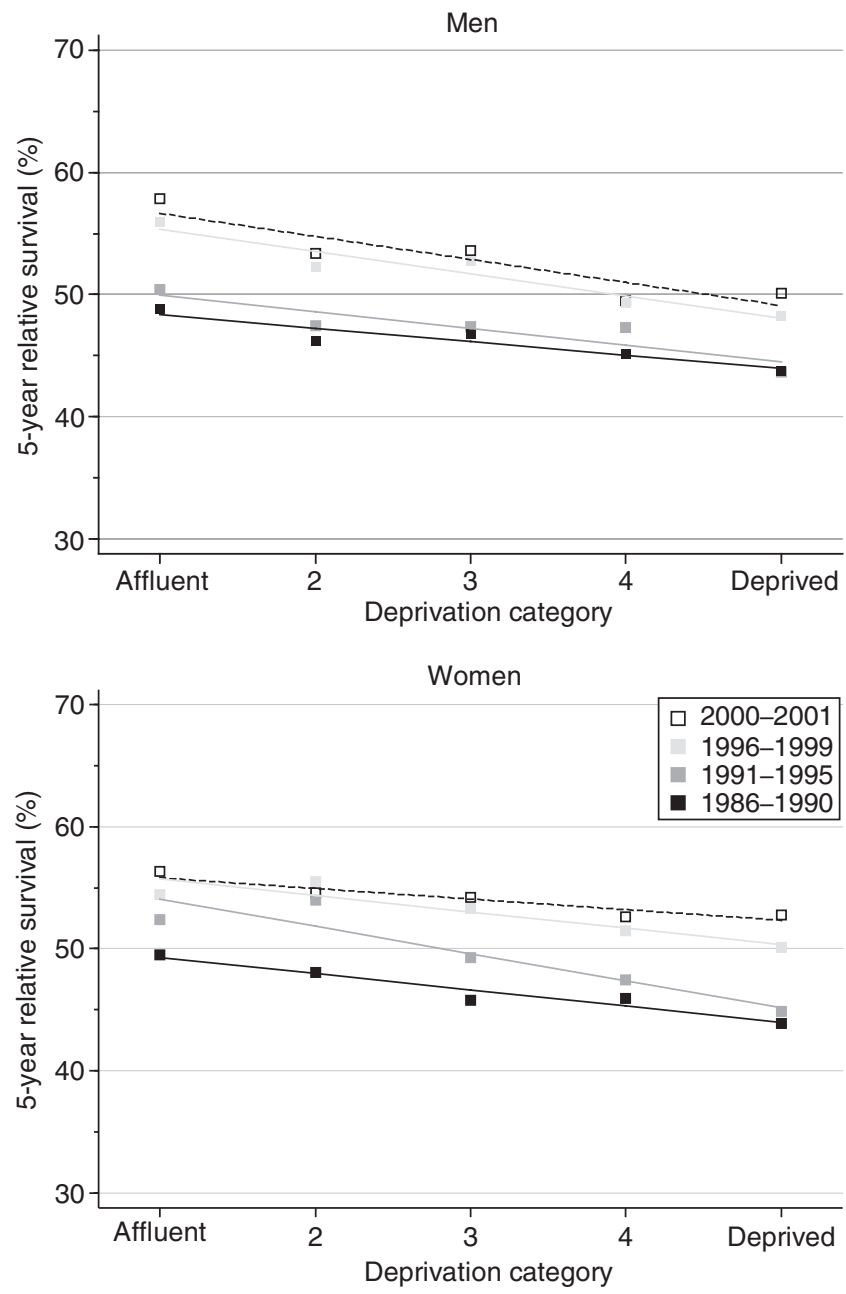

Figure $\mathbf{2}$ Trends in the deprivation gap in 5-year relative survival (\%) by sex and calendar period of diagnosis: England and Wales, adults (15-99 years) diagnosed during 1986-1999 and followed up to 2001 .

After adjusting for temporal trends in survival, the fitted deprivation gap is statistically significant in every case, with the exception of 10-year survival for patients diagnosed during $1986-1990$. 
Table 2 Trends in the deprivation gap in relative survival (\%) by sex, time since diagnosis and calendar period of diagnosis: England and Wales, adults (I5-99 years) diagnosed during 1986-1999 and followed up to 2001

\begin{tabular}{|c|c|c|c|c|c|c|c|c|c|c|c|}
\hline \multirow[b]{3}{*}{$\begin{array}{l}\text { Time since } \\
\text { diagnosis }\end{array}$} & & \multicolumn{6}{|c|}{ Calendar period of diagnosis ${ }^{a}$} & \multirow{2}{*}{\multicolumn{2}{|c|}{ 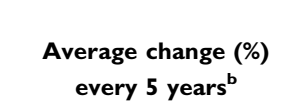 }} & \multirow{2}{*}{\multicolumn{2}{|c|}{$\begin{array}{c}\text { Prediction }{ }^{c} \text { for patients } \\
\text { diagnosed during 2000-200 I }\end{array}$}} \\
\hline & & \multicolumn{2}{|c|}{$1986-1990$} & \multicolumn{2}{|c|}{$1991-1995$} & \multicolumn{2}{|c|}{$1996-1999$} & & & & \\
\hline & & $\begin{array}{l}\text { Deprivation } \\
\text { gap (\%) }\end{array}$ & $95 \% \mathrm{Cl}$ & $\begin{array}{l}\text { Deprivation } \\
\text { gap (\%) }\end{array}$ & $95 \% \mathrm{Cl}$ & $\begin{array}{l}\text { Deprivation } \\
\text { gap (\%) }\end{array}$ & $95 \% \mathrm{Cl}$ & $\begin{array}{l}\text { Deprivation } \\
\text { gap (\%) }\end{array}$ & $95 \% \mathrm{Cl}$ & $\begin{array}{l}\text { Deprivation } \\
\text { gap (\%) }\end{array}$ & $95 \% \mathrm{Cl}$ \\
\hline \multirow[t]{2}{*}{ I year } & Men & $-5.1 * *$ & $(-7.6,-2.5)$ & $-7.7 * *$ & $(-10.0,-5.5)$ & $-5.9 * *$ & $(-8.3,-3.6)$ & -0.4 & $(-2.2,1.4)$ & $-6.7 * *$ & $(-9.9,-3.4)$ \\
\hline & Women & $-5.0 * *$ & $(-7.7,-2.2)$ & $-8.0 * *$ & $(-10.4,-5.6)$ & $-5.7 * *$ & $(-8.1,-3.2)$ & -0.3 & $(-2.3,1.6)$ & $-4.7 * *$ & $(-8.1,-1.3)$ \\
\hline \multirow[t]{2}{*}{5 years } & Men & $-4.4 * *$ & $(-7.3,-1.5)$ & $-5.5 * *$ & $(-8.1,-2.9)$ & $-7.3 * *$ & $(-10.4,-4.1)$ & -1.5 & $(-3.8,0.7)$ & $-7.5 * *$ & $(-11.5,-3.6)$ \\
\hline & Women & $-5.3 * *$ & $(-8.4,-2.2)$ & $-8.9 * *$ & $(-11.6,-6.1)$ & $-5.4 * *$ & $(-8.9,-1.9)$ & -0.4 & $(-2.8,2.1)$ & -3.5 & $(-7.6,0.7)$ \\
\hline \multirow{2}{*}{10 years } & Men & -2.1 & $(-5.2,1.0)$ & $-4.9 * *$ & $(-7.9,-1.8)$ & & & -2.7 & $(-7.1,1.6)$ & $-7.0 * *$ & $(-11.5,-2.5)$ \\
\hline & Women & -2.7 & $(-6.0,0.5)$ & $-8.7 * *$ & $(-12.2,-5.3)$ & & & $-6.0 *$ & $(-10.7,-1.3)$ & $-8.2 * *$ & $(-12.9,-3.4)$ \\
\hline
\end{tabular}

$\mathrm{Cl}=$ confidence interval. ${ }^{a}$ Survival estimated with cohort or complete approach (see Rachet et al, 2008). ${ }^{b}$ Mean absolute change (\%) in the deprivation gap in survival every 5 years, adjusted for the underlying trend in survival (see Rachet et al, 2008). 'Survival estimated with hybrid approach (see Rachet et al, 2008). * $P<0.05$; ** $P<0.01$.

The deprivation gap in survival has remained fairly stable: the slight widening (approximately $-1 \%$ every 5 years) is not statistically significant (Table 2). The exception here is 10 -year survival for women, where the deprivation gap has increased significantly.

Short-term predictions with hybrid analysis suggest that the socioeconomic differences in survival up to 10 years after diagnosis are likely to remain wide for the foreseeable future (Table 2)

\section{COMMENT}

Steadily improving survival for patients with non-Hodgkin lymphoma in England and Wales during the 1990s continues a trend that has been evident for more than 20 years. Five-year survival for patients diagnosed during the early 1970s was approximately $30 \%$, reaching $40-45 \%$ in the 1980 s (Coleman et al, 1999) and now $52 \%$ for patients diagnosed in the late 1990s. This steady trend probably reflects progress in treatment, especially radiotherapy and chemotherapy, since the early 1980s. Survival in England and Wales is still lower than, although close to, figures reported from other western European countries (Sant et al, 2003).

The improvement in overall survival has not led to greater equity in outcome. Survival for the least affluent remains substantially lower than for the most affluent, even after adjustment for the differences and trends in background mortality among deprivation categories; without that adjustment, the observed difference in survival would be even greater.

\section{REFERENCES}

Blair A, Kazerouni N (1997) Reactive chemicals and cancer. Cancer Causes Control 8: $473-490$

Brenner H, Rachet B (2004) Hybrid analysis for up-to-date long-term survival rates in cancer registries with delayed recording of incident cases. Eur J Cancer 40: 2494-2501

Coleman MP, Estève J, Damiecki P, Arslan A, Renard H (1993) Trends in Cancer Incidence and Mortality (IARC Scientific Publications No. 121). International Agency for Research on Cancer: Lyon

Coleman MP, Babb P, Damiecki P, Grosclaude PC, Honjo S, Jones J, Knerer G, Pitard A, Quinn MJ, Sloggett A, De Stavola BL (1999) Cancer Survival Trends in England and Wales 1971-1995: Deprivation and NHS Region. Studies on Medical and Population Subjects No. 61. The Stationery Office: London

IARC (1996) IARC Monographs on the Evaluation of Carcinogenic Risks to Humans. Volume 67. Human Immunodeficiency Viruses and Human T-cell Lymphotropic Viruses. International Agency for Research on Cancer: Lyon

IARC (1998) IARC Monographs on the Evaluation of Carcinogenic Risks to Humans. Volume 70. Epstein-Barr Virus and Kaposi's Sarcoma Herpesvirus/ Human Herpesvirus 8. International Agency for Research on Cancer: Lyon

Lynge E, Anttila A, Hemminki K (1997) Organic solvents and cancer. Cancer Causes Control 8: 406-419

Metayer C, Johnson ES, Rice JC (1998) Nested case-control study of tumors of the hemopoietic and lymphatic systems among workers in the meat industry. Am J Epidemiol 147: 727 -738

Percy CL, O'Conor G, Gloeckler Ries LA, Jaffe ES (1984) Non Hodgkin's lymphomas. Application of the international classification of diseases for oncology (ICD-O) to the 'Working Formulation'. Cancer 54: 1435-1438

Quinn MJ, Babb P, Brock A, Kirby L, Jones J (2001) Cancer Trends in England and Wales 1950-1999. Studies on Medical and Population Subjects No. 66. Office for National Statistics: London

Rachet B, Woods LM, Mitry E, Riga M, Cooper N, Quinn MJ, Steward J, Brenner H, Estève J, Sullivan R, Coleman MP (2008) Cancer survival in England and Wales at the end of the 20th century. $\mathrm{Br} J$ Cancer 99(Suppl 1): S2-S10

Sant M, Aareleid T, Berrino F, Bielska Lasota M, Carli P-M, Faivre J Grosclaude PC, Hédelin G, Matsuda T, Møller H, Moller T, Verdecchia A, Capocaccia R, Gatta G, Micheli A, Santaquilani M, Roazzi P, Lisi D, EUROCARE Working Group (2003) EUROCARE-3: survival of cancer patients diagnosed 1990-94-results and commentary. Ann Oncol 14(Suppl 5): $61-118$

Stellman JM (1998) Encyclopaedia of Occupational Health and Safety. 4th edn. International Labour Office: Geneva 